\title{
Crenças e Práticas de Mães sobre o Desenvolvimento Infantil nos Contextos Rural e Urbano
}

\author{
Mothers' Beliefs and Practices about Child Development \\ in Rural and Urban Contexts
}

\author{
Ana Paula Ribeiro Kobarg \& Mauro Luis Vieira* \\ Universidade Federal de Santa Catarina, Florianópolis, Brasil
}

\begin{abstract}
Resumo
A presente pesquisa teve como objetivo investigar a correlação entre as crenças e práticas de cuidado materno em diferentes contextos no município de Itajaí. Participaram da pesquisa setenta e sete mães que responderam a um questionário. Através da análise dos dados constatou-se que: mães da zona urbana, com escolaridade superior, valorizaram mais o fator Estimulação, enquanto mães da zona urbana, com baixa escolaridade, se destacaram em relação ao fator Disciplina; o tempo que as mães passavam com os filhos na zona rural foi significativamente maior em comparação com mães dos outros grupos; e mães da zona urbana com baixa escolaridade relataram que seus filhos brincavam significativamente mais com outras crianças. Portanto, concluise que crenças e práticas de cuidado materno apresentam configurações diferentes em função do contexto em que as mães residem.

Palavras-chave: Crenças maternas; cuidado parental; contextos; desenvolvimento infantil.
\end{abstract}

\begin{abstract}
The purpose of this study was to investigate the correlation of the beliefs and practices of maternal care in rural and urban contexts in the city of Itajaí, SC. Seventy-seven mothers were asked to participate in the study by filling in a questionnaire. The following points were observed through the analysis of the results: Urban mothers with high educational level attributed significantly more value to the factor of stimulation, whereas urban mothers with a lower educational level gave more importance to the factor of discipline. The amount of time that mothers spent with their children in the countryside was significantly greater in relation to mothers in the other group. Urban mothers of lower educational level said that their children played significantly more with other children. Therefore, it was concluded that practical beliefs and maternal care practices show different configurations regarding the contexts the mothers dwelling.

Keywords: Maternal beliefs; parental care; contexts; child development.
\end{abstract}

O comportamento parental, comum no ser humano, tem importante função adaptativa no sentido de promover a sobrevivência dos indivíduos e da espécie humana de modo geral. No entanto, existem especificidades nesse cuidado que dependem da cultura e do contexto familiar. Embora os modelos culturais de pais possam ser supostamente estáveis e consistentes, eles estão integrados nas dinâmicas culturais em que se desenvolvem e mudam com o tempo histórico, em conjunção com mudanças sociodemográficas. Partindo desse pressuposto, cada fase de desenvolvimento histórico vem produzindo diferentes idéias acerca dos cuidados e metas parentais. Épocas históricas (ex: períodos de guerra) também constituem meio ambientes culturais, quando as estratégias parentais necessitam ser adaptadas (Keller, 2007).

*Endereço para correspondência: Departamento de Psicologia da Universidade Federal de Santa Catarina, Campus Universitário, Trindade, Florianópolis, SC, 88040-900. Tel.: (48) 3721 8606. E-mail: mvieira@cfh.ufsc.br
O comportamento dos pais não consiste de uma série de respostas acidentais ao comportamento de seus filhos. Os pais têm noções ou idéias a respeito de como devem tratar seus filhos, isto é, com base no que acreditam ser bom ou ruim, naquilo que eles valorizam ou desvalorizam e que norteiam suas práticas na relação com os filhos (Kobarg, Sachetti, \& Vieira, 2006).

\section{Valores e Crenças Parentais sobre o Desenvolvimento Infantil}

O papel e a importância da crença, particularmente para o comportamento dos pais, vêm sendo extensamente pesquisados (Goodnow \& Collins, 1990; Harkness \& Super, 1996; Siegel \& McGullicuddy-DeLisi, 2002). Alguns autores, como D'Andrade (1987) e Harkness e Super (1996), salientam que as crenças subsidiam o comportamento do indivíduo, que essas são mais implícitas do que explícitas e que estão ligadas ao comportamento. Goodnow (1992) sumariza quatro razões para se estudar e aprofundar 
o conhecimento das crenças parentais: (a) elas são uma interessante forma de cognição e desenvolvimento do adulto, (b) mostram um caminho para ajudar a compreender as ações dos pais, (c) são aspectos do contexto no qual a criança vive e (d) podem indicar direções nos processos de transmissão e mudança cultural.

A utilização do termo "crença" é controversa. Por exemplo, Goodnow e Collins (1990) rejeitam a expressão "sistemas de crença," preferindo o termo "idéias," embora, ocasionalmente, utilizem o termo "cognição" ou "expectativas." Esses autores ressaltam que "idéias" não têm uma conotação de "inércia," ao contrário, transmite a noção de ação e algum grau de sentimento. Já Harkness e Super (1996) preferem o termo "etnoteoria," apesar de fazerem uso de "sistema cultural de crença" no próprio título do livro do qual são organizadores, argüindo que este é mais facilmente identificado pelos leitores. Palácios (1990), por sua vez, refere-se a "processos cognitivos," "crenças" e "idéias" indistintamente. Contudo, há quem enfatize a necessidade de uma análise conceitual desses termos para uma designação mais precisa dos fenômenos aos quais eles se referem (Bastos, 1991).

Partindo do princípio de que os pais agem com seus filhos em função de crenças desenvolvidas através das vivências e experiências sociais e culturais ao longo de suas vidas, revisões recentes da literatura sobre o tema ( $\mathrm{R}$. C. Ribas Jr., 2004; Siegel \& McGillicuddy-De Lisi, 2002) têm revelado que existem controvérsias em torno da melhor maneira de definir as cognições parentais e, ainda, conceitos correlatos, como crenças parentais. No entanto, há certo consenso entre os referidos pesquisadores de que essas cognições atuam como mediadores, influenciando práticas de cuidado e comportamentos parentais. Essas crenças, por sua vez, acabam tendo efeitos diversos sobre o comportamento das crianças e o desenvolvimento infantil (R. C. Ribas Jr., Seidl de Moura, \& Bornstein, 2003).

Nesse sentido, Martin e Johnson (1992) encontraram uma relação entre as crenças maternais sobre o desenvolvimento e a percepção materna da competência infantil: mães com um conhecimento mais sofisticado sobre teorias do desenvolvimento infantil e da aprendizagem tenderiam a perceber as crianças como mais competentes, embora não sejam evidentes os mecanismos subjacentes a essa relação. Como apontado também por pesquisas nacionais, é possível que as mães com teorias mais sofisticadas sejam estimuladas, como efeito de suas crenças, a se tornarem mais observadoras de suas crianças, embora uma direção inversa de causalidade seja também plausível (Braz, Dessen, \& Silva, 2005; Rabinovich, 1998, 1999; Seidl de Moura et al., 2004).

Um dos fatores que poderiam ajudar a explicar as diferenças nas crenças sobre cuidados parentais e o desenvolvimento infantil é o nível de escolaridade (Keller et al., 2006; R. C. Ribas Jr. et al., 2003). Esse argumento é confirmado por pesquisas realizadas no Brasil (Lordelo, Fonseca, \& Araújo, 2000; R. C. Ribas Jr. et al., 2003; Ruella, 2006; Seidl de Moura et al., 2004) e no exterior (Miller, 1988; Suizzo, 2002). No caso específico do estudo realizado por
Seidl de Moura et al. (2004), foi encontrado que a escolaridade estava correlacionada com as cognições parentais e com conhecimentos sobre desenvolvimento infantil. Nesse sentido, pode-se dizer que a escolaridade parental é uma variável importante no contexto de desenvolvimento.

Para investigar a correlação entre as crenças e práticas de cuidado materno em diferentes contextos de desenvolvimento, o presente estudo apóia-se no modelo de Nichos de Desenvolvimento (Harkness \& Super, 1994, 1996; Harkness et al., 2001; Harkness, Super, \& van Tijen, 2000). Através desse modelo, pressupõe-se que as crenças, como parte da psicologia dos cuidadores, afetarão as práticas de cuidado (e vice-versa), e, assim como as práticas e crenças, transformarão e serão transformadas pelo ambiente físico e social. É nessa dinâmica complexa que se situa o desenvolvimento infantil.

As etnoteorias parentais são modelos culturais que representam uma série de idéias (conscientes ou não) que pais e mães têm sobre crianças e famílias, e concepções sobre como os filhos devem ser criados. O estudo desses modelos pode contribuir para a compreensão de como é estabelecida a vida diária das crianças e como se expressa em hábitos de cuidado rotineiros e que devem ser compreendidos em função do ambiente em que a criança vive.

\section{Contextos de Desenvolvimento}

Através de estudos transculturais, é possível evidenciar correlações entre valores culturais e padrões específicos de educação de crianças. Kagitçibasi (1996) demonstrou, a partir de pesquisas empíricas, que dimensões do processo de socialização, como autonomia, independência, controle, competência e realização, assumem significados diversos dependendo do contexto.

Uma abordagem cultural deve levar em conta que comunidades culturais distintas podem esperar que as crianças desenvolvam atividades em momentos muito diferentes durante a infância e se surpreender com as normas de desenvolvimento de outras comunidades (Rogoff, 2005). Uma questão importante para qualquer comparação ou discussão entre diferentes comunidades deve ser a relativização do que é observado e registrado em cada contexto (Cole \& Means, 1981).

Os sistemas de cuidado à criança têm sido relacionados a resultados desenvolvimentais diferenciados nas áreas cognitiva, social e afetiva e que devem ser compreendidos em função do contexto. Por exemplo, Baumrind (1993) revisou um conjunto de estudos que apontam para a importância crucial das variações ambientais, incluindo detalhes do processo de socialização, no desenvolvimento da criança, com destaque para as crenças parentais sobre a sua própria efetividade enquanto agentes com poder de influência.

Na teoria ecológica de Bronfenbrenner (1979/1996) há uma ênfase na relação de reciprocidade entre os indivíduos e o contexto físico, temporal, social e simbólico. Por exemplo, mãe, pai e filho(a) se interinfluenciam, assim como são influenciados por outras pessoas, não necessa- 
Kobarg, A. P. R. \& Vieira, M. L. (2008). Crenças e Práticas de Mães sobre o Desenvolvimento Infantil nos Contextos Rural e Urbano.

riamente presentes no ambiente físico imediato. O estudo da relação diádica entre mãe/pai e filho(a) poderá levar à compreensão das mudanças no desenvolvimento da criança, mas também dos adultos que cuidam dela e do ambiente em que está inserida.

A partir das considerações anteriormente mencionadas, é razoável pensar que o contexto vai influenciar a forma como o cuidado parental será exercido. Na presente pesquisa, dados sobre crenças e práticas de mães sobre o desenvolvimento infantil poderão ser diferentes, dependendo do contexto onde as famílias vivem (rural ou urbano). Esses contextos foram escolhidos, com base em estudos de Kagitçibasi (1996, 2005), por apresentarem diferenças marcantes na forma de organização social. Pode-se afirmar que entre as diferenças marcantes entre o contexto rural e urbano está a grande diversidade de opções sociais, econômicas, educacionais e a alta densidade populacional que se encontram nos centros urbanos (Albuquerque \& Pimentel, 2004; Caiado, Costa, \& Santos, 2003).

Partindo do pressuposto de que conhecer os aspectos do nicho de desenvolvimento de crianças brasileiras permitirá a ação efetiva de pesquisadores e profissionais de saúde no trabalho com famílias, a presente pesquisa tem como objetivo investigar crenças e práticas de cuidados maternos sobre desenvolvimento infantil nos contextos rural e urbano.

\section{Método}

Trata-se de uma pesquisa descritiva, exploratória e transversal, pois teve como objetivo descrever as características das crenças parentais sobre o desenvolvimento infantil em contextos distintos, visando uma compreensão da influência do meio na construção de crenças parentais. O delineamento é transversal, pois a ênfase na coleta dos dados estava centrada em um momento específico na vida das pessoas entrevistadas.

\section{Participantes}

Para a realização deste estudo, foram escolhidas famílias que residiam na zona rural e urbana do município de Itajaí, localizado no litoral do estado de Santa Catarina. Participaram da pesquisa 77 mães: 40 mães da zona urbana (ZU), que foram diferenciadas segundo a escolaridade: 20 mães apresentavam baixa escolaridade (Ensino Fundamental incompleto - ZUBE) e 20 com escolaridade superior (com Ensino Superior - ZUES). As outras 37 mães residiam na zona rural (ZR). Nesse caso, não houve divisão das mães em dois subgrupos, pois não havia diferença marcante entre o nível de escolaridade. Essas mães tinham no máximo Ensino Fundamental completo. Uma das possíveis explicações talvez seja o distanciamento da localidade em que essas mães residem da região metropolitana. As mães selecionadas tinham pelo menos um filho na idade de 0 a 3 anos. Quando a mãe tinha mais de um filho, um deles foi escolhido (através de sorteio) como criança foco.

No período de realização da pesquisa, a ampla maioria das mães era casada (54), 14 moravam junto (união está- vel), 8 eram solteiras e apenas uma era separada. As mães da zona rural tinham idades variando entre 18 e 47 anos e a média de idade foi de aproximadamente 29 anos. As mães da zona urbana com baixa escolaridade possuíam idade entre 19 e 37 anos e média de idade de 28 anos, enquanto as mães da zona urbana com escolaridade superior apresentavam idade entre 23 e 43 anos (média de idade de aproximadamente 32 anos).

\section{Instrumentos}

Dados demográficos. Para a coleta dos dados sociodemográficos foi utilizada uma ficha de informações sobre a família. Os dados coletados foram: escolaridade, número de filhos, estado civil, idade da mãe, bem como o sexo e a idade da criança focal. Também foram coletadas informações sobre a rotina da mãe e da criança focal. Foi solicitado que as mães organizassem, em uma tabela, os períodos do dia (manhã, tarde ou noite) em que ficavam com os filhos. Para tanto, as mães assinalavam os períodos que disponibilizavam para estar com seus filhos durante os dias da semana e durante os finais de semana. As mães também deveriam responder se elas ficavam sozinhas com a criança durante o período em que estavam em casa. Caso não fosse ela, a mãe deveria responder quem era a pessoa que ficava com a criança nesse período.

Também foi registrado no instrumento quanto tempo a mãe despendia para a criança e para os afazeres da casa ou outras atividades. Para responder a essas questões, a mãe deveria atribuir uma nota de 1 a 7 para mensurar o tempo que ela se ocupa com aquela atividade, sendo que 1 seria "nada" e 7 "muito."

Crenças maternas. Para identificar as crenças maternas, foi utilizada uma adaptação do instrumento desenvolvido por Suizzo (2002): Croyances es idées sur lês nourissons et petits enfants (CINPE). Essa escala foi validada para o Brasil, sendo intitulada "Inventário de crenças parentais sobre crianças e bebês" e utilizada em estudo anterior (Seidl de Moura et al., 2004). O instrumento consiste em 50 itens, 25 relacionados a bebês até 1 ano de idade, e 25 para crianças entre 1 e 3 anos. Conforme a escala original de Suizzo (2002), é possível identificar quatro dimensões relacionadas a diferentes domínios do cuidado parental: (a) Expor a criança a diferentes estímulos (Estimulação): a ênfase está relacionada com práticas que estimulem o desenvolvimento cognitivo e motor da criança, como por exemplo, oferecer brinquedos que estimulem seus sentidos e ler histórias para a criança. (b) Garantir a apresentação apropriada da criança: está relacionado com práticas orientadas para boa higiene da criança em lugares públicos e ênfase nos comportamentos socialmente aceitáveis, tais como, dar banho na criança e ensiná-la a agradecer e a cumprimentar; outro exemplo é ensinar a criança a se comportar fora de casa. (c) Responder à criança e criar vínculo com ela (Responsividade): ser responsivo para a criança, como por exemplo, ficar com o bebê no colo e não deixar a criança ver os pais brigando. (d) Manter o controle sobre criança (Disciplina): está relacionado com práticas de disciplina, tais como corrigir a criança quando ela faz 
alguma coisa errada. Para cada assertiva, a mãe devia assinalar a importância que atribuía ao item, numa escala de 6 pontos (1="não concordo"; 6="é extremamente importante"). Foi solicitado que a mãe respondesse de acordo com o que pensava sobre a criação de crianças em geral, e não com o que especificamente fazia com sua criança. Esse procedimento foi adotado, pois permite identificar as crenças parentais sobre desenvolvimento infantil em geral, não se restringindo apenas às particularidades da vida de cada indivíduo.

\section{Procedimentos}

A pesquisa foi submetida ao Comitê de Ética da Universidade Federal de Santa Catarina, onde obteve aprovação através do protocolo de número 368/2005. Todos os participantes receberam informações orais e escritas sobre os objetivos da pesquisa, responsabilidade do pesquisador, método empregado e direito a recusar o consentimento. A inclusão na pesquisa foi condicionada à assinatura do Termo de Consentimento Informado.

A especificidade de cada universo social em que se penetra requer procedimentos diferenciados que só se tornam efetivos através do olhar treinado do observador, que vai capturando o que pode ser significativo e apreendendo os códigos que perpassam as relações. Para o grupo ZUES, as mães foram contatadas através de amostra por conveniência. Para o grupo ZUBE, o acesso às mães foi através de creches públicas. Quanto ao grupo ZR, a inexistência de listas de endereços atualizados, ou de quaisquer outras listagens que possibilitassem a localização de parcelas dessa população, dificultou a seleção prévia de qualquer amostra domiciliar, exigindo-se para isto visita "direta" às famílias.

\section{Análise dos Dados}

Os cálculos estatísticos foram realizados através do software SPSS 11.0. Os dados sociodemográficos foram analisados, principalmente, em termos de escolaridade das mães, relacionando esta variável com outras do estudo (por exemplo, estado civil, número de filhos, idade da mãe e os escores dos quatro fatores do questionário sobre práticas parentais) através de análises de correlação. Em relação aos dados da rotina da mãe e da criança focal, calculou-se a média das respostas que as mães assinalaram em relação à rotina da criança.

A análise dos itens do inventário sobre práticas parentais foi feita com base nos quatro fatores apontados por Suizzo (2002): (a) Estimulação (itens de 1 a 16); (b) Apresentação apropriada do bebê em público (itens de 17 a 24); (c) Responsividade (itens de 25 a 32); e (d) Disciplina (itens 33, 36, 37, 39, 40, 41, 42 e 43). Apenas os itens que tiveram carga fatorial igual ou maior do que 0.3 e que entraram em apenas um fator foram considerados.

Foi obtido um escore para cada fator através do somatório dos itens e, posteriormente, dividido pelo número de itens correspondente a cada fator. O objetivo desse procedimento foi para obter a média. A análise de variância (ANOVA) foi utilizada para fazer comparações entre os quatro fato- res. Foi utilizado também, para determinar o grau de correlação, o teste de correlação de Pearson entre os dados sociodemográficos e os quatro fatores. Em todas as análises adotou-se um $\alpha$ de no mínimo 0,05 .

\section{Resultados}

\section{Dados sobre a Rotina da Mãe e da Criança Focal}

As mães da ZR disponibilizavam maior tempo para a criação dos filhos, sendo que 34 mães (91\%) ficavam em casa os três períodos do dia, durante a semana, e mais duas, totalizando 36 mães (97\%), nos fins de semana. Na ZUBE, as mães passavam menos tempo com a criança focal. Nove mães $(45 \%)$ ficavam "manhã/tarde e noite," $7(35 \%)$ permaneciam com a criança focal apenas à noite e $3(15 \%)$ de manhã e de noite. Nos fins de semana, 20 mães (100\%) ficavam em tempo integral com a criança focal. Na ZUES, durante a semana, 9 mães (45\%) ficavam com a criança focal apenas de manhã e à noite e $2(10 \%)$ em período integral, 7 (35\%) apenas durante a noite e $2(10 \%)$ somente pela manhã ou só à tarde. Contudo, nos fins de semana todas as 20 mães (100\%) ficavam com a criança focal em período integral.

Através da análise de variância constatou-se que as mães da ZR despendiam maior tempo em atividades domésticas, enquanto as mães da ZUES dedicavam menos tempo aos afazeres domésticos $\left[F_{(2,74)}=9,89 ; p<0,05\right]$. Além disso, atividades rotineiras no cuidado com a criança (ex: banho, vestir) eram significativamente menos freqüentes no grupo de mães ZUES $\left[F_{(2,74)}=3,28 ; p<0,05\right]$.

Com relação à rotina da criança, constatou-se que filhos de mães da ZUBE eram os que brincavam mais com outras crianças em relação às crianças dos outros dois contextos $\left[F_{(2,74)}=4,41 ; p<0,05\right]$. No contexto das mães da ZUES as crianças tinham esse contato apenas quando freqüentavam escolas, e na ZR a própria organização espacial dificulta essa dinâmica. No entanto, independentemente do contexto e do tempo disponível para estar com a criança e dar conta das atividades domésticas, não houve diferença significativa nas respostas que as mães deram sobre o tempo que brincavam com a criança $\left[F_{(2,73)}=0,48 ; p\right.$ $>0,05]$.

\section{Crenças sobre Práticas Parentais}

As mães da ZR e ZUBE tenderam a valorizar mais a Apresentação apropriada do bebê em público e depois a Estimulação. Contudo, as mães da ZUES valorizaram mais a estimulação, porém, atribuíram também elevado grau de importância para a Apresentação do bebê em público. $\mathrm{O}$ fator Responsividade foi de razoável importância nos três grupos e o fator Disciplina foi o menos valorizado. Esses dados podem ser visualizados na Tabela 1 .

Foi realizada uma análise de variância (ANOVA) entre os três grupos de mães tendo como base os quatro fatores. A comparação entre os grupos de mães mostrou diferença significativa nos fatores Estimulação e Disciplina. Constatada a diferença, foi utilizado o teste post-hoc (DHS de Tukey) para verificar em que comparação de grupos, dois 
Kobarg, A. P. R. \& Vieira, M. L. (2008). Crenças e Práticas de Mães sobre o Desenvolvimento Infantil nos Contextos Rural e Urbano.

Tabela 1

Escores (em Termos de Média e Desvio Padrão) obtidos pelas Mães dos Diferentes Grupos em Relação aos Fatores do Inventário sobre Crenças e Práticas Maternas

\begin{tabular}{lllll}
\hline & $\mathrm{M}( \pm \mathrm{DP})$ & $\mathrm{M}( \pm \mathrm{DP})$ & $\mathrm{M} \quad( \pm \mathrm{DP})$ & \\
\hline Estimulação & $4,59 \pm 0,56$ & $4,95 \pm 0,40$ & $5,54 \pm 0,30$ & $21,43 *$ \\
Apresentação & $5,19 \pm 0,73$ & $5,40 \pm 0,35$ & $5,46 \pm 0,36$ & 0,10 \\
Responsividade & $4,28 \pm 0,64$ & $4,55 \pm 0,72$ & $4,51 \pm 0,43$ & 0,01 \\
Disciplina & $3,65 \pm 0,73$ & $4,11 \pm 0,48$ & $3,46 \pm 0,67$ & $8,51^{*}$ \\
\hline
\end{tabular}

Nota. ${ }^{*} p<0,05$.

Tabela 2

Correlações entre os Dados Sociodemográficos e os Fatores do Inventário sobre Crenças e Práticas Maternas no Grupo de Mães da Zona Rural.

$\begin{array}{lllllllll}1 & 2 & 3 & 4 & 5 & 6 & 7 & 8\end{array}$

1 - Número de filhos

2 - Estado civil ${ }^{\mathrm{a}} \quad-0,03$

3 - Escolaridade materna ${ }^{\mathrm{b}} \quad-0,35 * \quad-0,12$

4 - Sexo da criança ${ }^{c} \quad 0,12 \quad-0,05 \quad 0,24$

5 - Idade da mãe $\quad 0,63 * * \quad-0,32 \quad-0,27$

6 - Estimulação $\quad 0,10 \quad-0,31 \quad-0,03$

7 - Apresentação $\quad 0,14 \quad-0,44 * * \quad 0,04$

8 - Responsividade $\quad 0,18 \quad-0,12 \quad-0,04$

9 - Disciplina $\quad-0,06 \quad-0,08 \quad 0,04$

0,26

$0,16 \quad 0,03$

$-0,11 \quad 0,10 \quad 0,68 * *$

$\begin{array}{llll}-0,02 & 0,09 & 0,60 * * & 0,50 * *\end{array}$

$\longrightarrow$

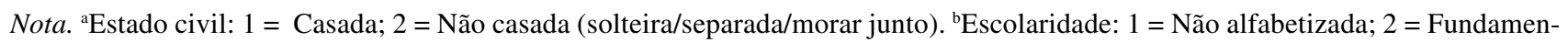
tal incompleto (até $4^{\mathrm{a}}$. Série); $3=$ Fundamental incompleto $\left(5^{\mathrm{a}}\right.$. $-8^{\mathrm{a}}$. Série); $4=$ Fundamental completo; $5=$ Ensino Médio incompleto; 6 = Ensino Médio completo; 7 = Superior incompleto; 8 = Superior completo; 9 = Pós-Graduação. 'Sexo da criança: $1=$ Feminino; $2=$ Masculino. ${ }^{*} p<0,05 ; * * p<0,01$.

Tabela 3

Correlações entre os Dados Sociodemográficos e os Fatores do Inventário sobre Crenças e Práticas Maternas no Grupo de Mães da Zona Urbana

\begin{tabular}{|c|c|c|c|c|c|c|c|c|}
\hline & 1 & 2 & 3 & 4 & 5 & 6 & 7 & 8 \\
\hline \multicolumn{9}{|l|}{1 - Número de filhos } \\
\hline 2 - Estado civil ${ }^{\mathrm{a}}$ & 0,03 & & & & & & & \\
\hline 3 - Escolaridade materna ${ }^{b}$ & 0,01 & $-0,03$ & & & & & & \\
\hline 4 - Sexo da criança ${ }^{c}$ & $-0,13$ & $-0,25$ & $-0,14$ & & & & & \\
\hline 5 - Idade da mãe & $0,33 *$ & $-0,13$ & $0,41 * *$ & $-0,02$ & & & & \\
\hline 6 - Estimulação & $-0,19$ & 0,09 & $0,69 * *$ & $-0,12$ & 0,27 & & & \\
\hline 7 - Apresentação & $-0,12$ & $-0,02$ & 0,23 & $-0,15$ & 0,03 & 0,31 & & \\
\hline 8 - Responsividade & $-0,02$ & 0,20 & 0,10 & $-0,03$ & 0,17 & 0,29 & 0,03 & \\
\hline 9 - Disciplina & $-0,08$ & 0,01 & $-0,57 * *$ & 0,13 & $-0,29$ & $-0,26$ & 0,10 & 0,10 \\
\hline
\end{tabular}

Nota.${ }^{a}$ Estado civil: 1 = Casada; 2 = Não casada (solteira/separada/morar junto). ${ }^{b}$ Escolaridade: 1 = Não alfabetizada; $2=$ Fundamental incompleto (até $4^{\mathrm{a}}$. Série); $3=$ Fundamental incompleto $\left(5^{\mathrm{a}}\right.$. $-8^{\mathrm{a}}$. Série); $4=$ Fundamental completo; $5=$ Ensino Médio incompleto; 6 = Ensino Médio completo; 7 = Superior incompleto; 8 = Superior completo; 9 = Pós-Graduação. ${ }^{\mathrm{c} S e x o}$ da criança: $1=$ Feminino; $2=$ Masculino. $* p<0,05 ; * *<<0,01$.

a dois, ela ocorreu. As diferenças significativas no fator Estimulação foram entre as mães da ZR e ZUES, e também entre as mães da ZUBE e ZUES, sendo que as mães da ZUES obtiveram maior escore de respostas para esse fator. No fator Disciplina, as diferenças significativas foram entre as mães da ZR e ZUES, e também entre as mães da ZUBE e ZUES. As mães da ZUBE obtiveram o maior escore de respostas neste fator, seguidas pelas mães da ZR. 
Quando realizadas as correlações entre os quatro fatores com as variáveis sociodemográficas, foi confirmada a relação entre o fator Estimulação e o nível de escolaridade das mães da ZU. Mães de maior escolaridade tenderam a valorizar significativamente mais a Estimulação. Por outro lado, no fator Disciplina, a relação foi inversa. Mães da ZU de menor escolaridade valorizavam significativamente mais a disciplina em comparação com as mães de outros contextos.

As correlações realizadas entre os dados sociodemográficos mostraram significância nos dados referentes à idade e o escore do nível de escolaridade apenas na ZU, demonstrando que mães de mais idade possuíam maior nível de escolaridade. Houve também correlação significativa entre idade e número de filhos nos dois contextos, indicando que mães de mais idade possuíam maior o número de filhos. Por outro lado, foi encontrada correlação negativa entre o número de filhos e a escolaridade apenas na $\mathrm{ZR}$, demonstrando que mães com maior número de filhos possuíam baixo grau de escolaridade.

Através da análise entre os fatores do inventário e os dados sóciodemográficos, no grupo de mães da ZR, o fator Apresentação correlacionou-se significativa e negativamente com o estado civil das mães. Nesse caso, mães casadas valorizaram mais a Apresentação do bebê em público do que as mães não casadas (solteiras/separadas/ morar junto com um companheiro). Também no contexto rural, a análise dos fatores entre si indicou haver correlação significativa e positiva entre Estimulação e Apresentação. Houve correlações significativas entre diferentes fatores, como por exemplo, quanto maior a Estimulação, maior a Apresentação, maior a Responsividade e maior a Disciplina.

No contexto urbano, houve correlação significativa e positiva do fator Estimulação com a escolaridade das mães. Contudo, no fator Disciplina foi encontrada uma correlação significativa, mas negativa com a escolaridade da mãe, mostrando que, quanto maior o grau de escolaridade, menor é a importância atribuída ao fator Disciplina. Ou seja, através de maior grau de escolaridade a mãe poderia estar aprendendo formas alternativas de educação dos filhos em detrimento da ênfase na disciplina.

É importante destacar que a variável sexo do bebê não foi correlacionada com outros dados sóciodemográficos e os fatores do inventário. Esse resultado deve ser melhor investigado em estudos posteriores, uma vez que esse dado não foi conclusivo, pois havia o dobro de meninas em relação aos meninos.

\section{Discussão}

Através das análises dos dados, foram encontradas diferenças significativas nas crenças e práticas de cuidados maternos sobre desenvolvimento infantil nos contextos rural e urbano. Uma das variáveis que teve efeito significativo foi a escolaridade materna. Por exemplo, mães da zona urbana, com escolaridade superior, valorizaram mais a estimulação de seus filhos em comparação com mães resi- dentes na cidade que tinham baixa escolaridade e mães residentes na zona rural. Esse dado vem ao encontro de outros estudos sobre crenças e práticas parentais, indicando que o grau de instrução interfere de modo significativo na relação entre as mães e os seus filhos (Bornstein, Hahn, Suizzo, \& Haynes, 2003; R. C. Ribas Jr. et al., 2003; Seidl de Moura et al., 2004). Ou seja, pode-se pensar que mães com grau de instrução mais elevado, além de se preocuparem com os cuidados básicos de seus filhos, também consideram importante oferecer a eles outros tipos de oportunidades que propiciem outras formas de interação com o contexto em que a criança vive, como por exemplo, a exploração do ambiente e a brincadeira.

Por outro lado, mães da zona urbana com baixa escolaridade deram mais ênfase ao fator Disciplina. Uma possível explicação para esse resultado pode ser dada pelo modo de vida dessas mães, que talvez valorizem de modo acentuado as regras e as normas impostas pela família, conforme apontam Braz et al. (2005). Esses autores afirmam que, de modo geral, em relação aos valores associados à educação de filhos, mães advindas de extratos socioeconômicos mais altos, consideram mais importante transmitir valores relativos à sociabilidade e à afetividade, enquanto as de extratos socioeconômicos mais baixos enfatizam a educação formal, o respeito e os valores morais. Tais orientações distintas sobre o que deve ser ensinado às crianças são coerentes com a literatura e dependem do nível socioeconômico e do que é esperado dos filhos no futuro (Tudge et al., 1999).

No caso de práticas de criação de crianças, Suizzo (2002) encontrou que mães e pais parisienses valorizavam mais, em média, práticas relacionadas à estimulação dos filhos, incluindo práticas de promoção do desenvolvimento. $\mathrm{O}$ segundo modelo cultural mais valorizado foi apresentação Apropriada do bebê em público, seguido de Responsividade e Vínculo.

Mais especificamente no caso do Brasil, através de pesquisa realizada na zona rural do estado do Rio de Janeiro com mães e avós, em que foi aplicado o "Inventário de crenças e práticas parentais sobre crianças e bebês" (mesmo instrumento utilizado na presente pesquisa), foi encontrado que os fatores mais valorizados foram Apresentação apropriada do bebê em público e Responsividade (Ruela, 2006). Visto que esses resultados contrastam com os da presente pesquisa, embora ambas tenham sido realizadas em ambiente rural do mesmo país, sugere-se que podemos encontrar mais diferenciações nas crenças parentais em um mesmo país do que normalmente se generaliza na literatura, em que autores estrangeiros apresentam as mães da América Latina, ou ainda do Brasil, sob um olhar homogêneo, conforme apontam A. F. P. Ribas e Seidl Moura (1999).

Comparando os resultados dos estudos anteriormente citados, nota-se o quanto o contexto cultural influencia o que os pais pensam sobre criação de filhos. As crenças sobre a educação das crianças podem variar em função das especificidades do ambiente social (Bornstein et al., 2003; Bronfenbrenner, 1979/1996). Por exemplo, com as mudanças no contexto social nas últimas décadas, em que mulhe- 
Kobarg, A. P. R. \& Vieira, M. L. (2008). Crenças e Práticas de Mães sobre o Desenvolvimento Infantil nos Contextos Rural e Urbano.

res estão ingressando no mercado de trabalho, têm-se estabelecido novas opções para o cuidado alternativo de bebês e crianças pequenas.

Em termos qualitativos, durante as entrevistas realizadas com as mães residentes na zona urbana com escolaridade superior, constatou-se que o contato com o(a) filho(a) e a preocupação com o que ele(a) estivesse fazendo eram mais intensos do que nas mães da zona urbana com baixa escolaridade e também em comparação com mães residentes na zona rural. Nesse último caso, embora as mães estivessem mais presentes em casa (muitas delas não trabalhavam fora), não se preocupavam com as solicitações das crianças ou em estimulá-las durante a entrevista. Essas mães demonstravam grande preocupação com seu bem-estar físico (mantendo um ambiente seguro, ex: crianças dentro de "chiqueirinhos"). Keller (2007), em pesquisa intracultural, com mães das zonas rural e urbana, em Camarões, revelou diferenças significativas com respeito aos sistemas parentais, que podem ser resumidos da seguinte maneira: as famílias rurais seguem um modelo interdependente, enquanto as mães urbanas educadas seguem uma combinação entre os modelos de interdependência e independência.

\section{Considerações Finais}

$\mathrm{Na}$ presente pesquisa, procurou-se evidenciar a importância de alguns tipos diferentes de contexto (rural e urbano) na influência de crenças e práticas de criação de filhos. Além disso, ou em decorrência desses contextos, outras variáveis também passam a ser determinantes. Por exemplo, em centros urbanos, as mães acabam tendo maiores possibilidades e oportunidades de investir em sua formação educacional e profissional. Essa condição acaba refletindo na ampliação das dimensões envolvidas no cuidado dos filhos. A ênfase não fica apenas no cuidado direto e básico, mas engloba também outros fatores como a estimulação, não só pela mãe, mas também indiretamente, quando a mãe tem condições de colocar seu filho ou filha em ambientes ricos em estimulação através de brinquedos e atividades diversificados, conforme salientado por Keller (2007).

Portanto, os resultados obtidos na presente pesquisa indicam que as mães tendem a se comportar diferencialmente segundo suas condições de vida. Nesse sentido, parece haver forte associação entre as crenças, relacionadas aos sistemas culturais nos quais são construídas e mantidas, e as práticas de cuidado da criança (Goodnow, 1992; Harkness \& Super, 1996; Keller, 2007).

É importante destacar que as comparações entre contextos não significam juízos de valores de que algumas mães são melhores do que outras. Apenas indicam que o contexto ecológico, social e cultural em que vivem acaba, de alguma forma, interferindo no que as mães pensam sobre cuidados parentais e desenvolvimento infantil. Próximos estudos devem investigar quais são as conseqüências dos diferentes tipos de crenças maternas sobre o desenvolvimento infantil.
O conhecimento da articulação entre cultura, crenças e práticas pode resultar em caminhos produtivos para abordar o que se pode constituir em um importante problema social. Se as práticas podem ser influenciadas pelas crenças, então seria possível conceber e testar modelos de atuação sobre o problema, focalizando cultura, crenças e práticas como um conjunto, de modo que alterações em um desses campos possam repercutir favoravelmente em outros.

Por outro lado, em termos metodológicos, embora o presente estudo tenha apresentado resultados consistentes para o avanço do conhecimento sobre crenças e práticas maternas, é necessário reconhecer as limitações desse estudo empírico e que possam servir de base para futuras pesquisas. Talvez a principal limitação esteja relacionada com a natureza do instrumento de coleta de dados. Além de respostas a questionários e inventários, outra fonte de informação relevante que poderia ser usada em futuras pesquisas para se caracterizar a relação mãe-criança é a observação direta em situações estruturadas ou semi-estruturadas. O objetivo seria investigar de que forma ocorre a relação entre o que as mães pensam e o que elas efetivamente fazem.

Por fim, ressalta-se o potencial uso desse conhecimento para profissionais ligados à área da saúde (psicólogos, agentes de saúde, entre outros), bem como profissionais ligados à área da educação. Ou seja, o conhecimento que mães e pais têm sobre desenvolvimento infantil e crenças sobre como seus filhos devem ser criados podem facilitar o trabalho dos profissionais acima citados, no sentido de compreender quais as concepções de mundo que essas famílias têm e quais as consequiências do modo de viver dessas famílias sobre saúde e doença.

\section{Referências}

Albuquerque, F. J. B., \& Pimentel, C. E. (2004). Uma aproximação semântica aos conceitos urbano, rural e cooperativa. Psicologia: Teoria e Pesquisa, 20, 175-182.

Bastos, A. C. C. (1991). Idéias sobre a criação de filhos: Uma invenção cultural. Psico, 22, 63-87.

Baumrind, D. (1993). The average expectable environment is not good enough: A response to Scarr. Child Development, 64, 1299-1317.

Bornstein, M. H., Hahn, C. H., Suizzo, M., \& Haynes, M. (2003). Mothers' knowledge about child development and childrearing: National and cross-national studies. Unpublished manuscript, National Institute of Child Health and Human Development.

Braz, M. P., Dessen, M. A. \& Silva, N. L. P. (2005). Relações conjugais e parentais: Uma comparação entre famílias de classes sociais baixa e média. Psicologia: Reflexão \& Crítica, 18 , 151-161.

Bronfenbrenner, U. (1996). A ecologia do desenvolvimento humano: Experimentos naturais e planejados (M. A. V. Veronese, Trad.). Porto Alegre, RS: Artes Médicas. (Original publicado em 1979)

Caiado, A., Costa, S. \& Santos, S. M. M. (2003). Fim da dicotomia rural-urbano? Um olhar sobre os processos socioespaciais. São Paulo Perspectiva, 17, 115-124.

Cole, M., \& Means, B. (1981). Comparative studies of foundations of language and thought (pp. 343-364). New York: Norton. 
D'Andrade, R. G. (1987). A folk model of mind. In D. Holland \& N. Quinn (Eds.), Cultural models in language and thought (pp. 112-148). New York: Cambridge University Press.

Goodnow, J. (1992). Parents' ideas, childrens' ideas: Correspondence and divergence. In I. E. Sigel, A. V. McGillicuddyDeLisi, \& J. J. Goodnow (Eds.), Parental belief systems: The psychological consequences for children (pp. 293-317). Hillsdale, NJ: Lawrence Erlbaum.

Goodnow, J., \& Collins, W.A. (1990). Development according to parents: The nature, sources, and consequences of parents ideas. Hillsdale, NJ: Lawrence Erlbaum.

Harkness, S., \& Super, C. M. (1994). Developmental niche: A theoretical framework for analyzing the household production of health. Social Science and Medicine, 38, 219-226.

Harkness, S., \& Super, C. M. (1996). Introduction. In S. Harkness \& C. M Super (Eds.), Parents' cultural belief systems: Their origins, expressions, and consequences (pp. 1-23). New York: The Guilford Press.

Harkness, S., Super, C., Axia, V., Eliaz, A., Palácios, J., \& WellesNyström, B. (2001). Cultural pathways to successful parenting. International Society for the Study of Behavioral Development Newsletter, 1(38), 9-13.

Harkness, S., Super, C., \& van Tijen, N. (2000). Individualism and the "Western Mind" reconsidered: American and Dutch Parents' ethnotheories of the child. New Directions for Child and Adolescent Development, 87, 23-40.

Kagitçibasi, Ç. (1996). Family and human development across cultures $-A$ view from other side. Mahwah, NJ: Lawrence Erlbaum.

Kagitçibasi, Ç. (2005). Autonomy and relatedness in cultural context - Implications for self and family. Journal of Crosscultural Psychology, 36, 403-422.

Keller, H. (2007). Cultures of infancy. Hillsdale, NJ; Lawrence Erlbaum.

Keller, H., Lamm, B., Abels, M., Yovsi, R., Borke, J., Jensen, H., Papaligoura, Z., et al. (2006). Cultural models, socialization goals, and parenting ethnotheories. Journal of Cross-Cultural Psychology, 37, 155-172.

Kobarg, A. P. R, Sachetti, V. A. R., \& Vieira, M. L. (2006). Valores e crenças parentais: Reflexões teóricas. Revista Brasileira de Crescimento e Desenvolvimento Humano, 16, 96-102.

Lordelo, E. R., Fonseca, A. L., \& Araújo, M. L. V. B. (2000). Responsividade do ambiente de desenvolvimento: Crenças e práticas como sistema cultural de criação de filhos. Psicologia: Reflexão e Crítica, 13, 73-80.

Martin, C. A., \& Johnson, J. E. (1992). Children's self-perceptions and mothers' belief about development and competencies. In I. E. Siegel, A. V. McGillicuddy-DeLisi, \& J. J. Goodnow (Eds.), Parental belief systems (pp. 95-113). Hillsdale, NJ: Lawrence Erlbaum.

Miller, S. A. (1988). Parents' beliefs about children's cognitive development. Child Development, 59, 259-285.

Palácios, J. (1990). Parents' ideas about the development and education of their children: Answers to some questions. International Journal of Behavioral Development, 13, 137-155.

Rabinovich, E. P. (1998). Modos de morar no Brasil e contexto de desenvolvimento. Temas em Psicologia, 6(2), 105-115.

Rabinovich, E. P. (1999). Estudo comparativo dos modos de dormir e de mamar de crianças brasileiras em contextos sóciofamiliares urbano e rural. Interfaces: Revista de Psicologia (Salvador), 2(1), 41-49.

Ribas, A. F. P., \& Seidl de Moura, M. L. (1999). Manifestações iniciais de trocas interativas mãe-bebê e suas transformações. Estudos de Psicologia (Natal), 4(2), 273-288.
Ribas, R. C., Jr. (2004). Cognições de mães brasileiras acerca da maternidade, da paternidade e do desenvolvimento humano: Uma contribuição ao estudo da Psicologia parental. Tese de Doutorado não-publicada, Universidade do Estado do Rio de Janeiro, RJ.

Ribas, R. C., Jr., Seidl de Moura, M. L., \& Bornstein, M. H. (2003). Socioeconomic status in Brazilian psychological research: II SES and parenting knowledge. Estudos de Psicologia (Natal), 8(3), 385-392.

Rogoff, B. (2005). A natureza cultural do desenvolvimento humano (R. C. Costa, Trad.). Porto Alegre, RS: Artmed.

Ruela, S. F. (2006). Um estudo intergeracional de crenças valorizadas por mães em uma comunidade rural do Rio de Janeiro. Dissertação de Mestrado não-publicada, Universidade do Estado do Rio de Janeiro, RJ.

Seidl de Moura, M. L., Ribas, R. C., Jr., Piccinini, C. A., Bastos, A. C. S., Magalhães, C. M. C., Vieira, M. L., et al. (2004). Conhecimento sobre desenvolvimento infantil em mães primíparas de diferentes centros urbanos do Brasil. Estudos de Psicologia (Natal), 9(3), 421-429.

Siegel, I. E., \& McGillicuddy-De Lisi, A. V. (2002). Parent beliefs are cognitions: The dynamic belief systems model. In M. H. Bornstein (Ed.), Handbook of parenting: Vol. 3. Being and becoming a parent (pp. 485-508). Mahwah, NJ: Lawrence Erlbaum.

Suizzo, M. (2002). French parent's cultural models and childrearing beliefs. International Journal of Behavioral Development, 26, 297-307.

Tudge, J., Hogan, D., Lee, S., Tammeveski, M. M., Kulakova, N., Snezhkova, I., \& Putnam, S. (1999). Cultural heterogeneity: Parental values and beliefs and their preschoolers' activities in the United States, South Korea, Russia, and Estonia. In A. Göncü (Ed.), Children's engagement in the world: Sociocultural perspectives (pp. 62-96). London: Cambridge University Press.
Recebido: 19/09/2007 $1^{a}$ revisão: 03/12/2007 $2^{a}$ revisão: $16 / 01 / 2008$ $3^{a}$ revisão: $20 / 02 / 2008$ Aceite final: 07/03/2008 